\title{
Effects of network reinforcement options on energy losses
}

\author{
Simon Blake $\bowtie$, Ilias Sarantakos, Phil Taylor \\ School of Electrical and Electronic Engineering, Newcastle University, Newcastle Upon Tyne, UK \\ $凶$ E-mail: Simon.blake@newcastle.ac.uk
}

\begin{abstract}
A methodology has been developed to compare different grid reinforcement solutions, ranging from conventional through hybrid to purely smart grid approaches. It evaluates alternative reinforcement solutions, subject to the constraints of the particular local network and situation. This methodology can be applied at all voltage levels and to both generic and actual networks. In the present study, it is applied to a representative medium voltage network of 4 feeders based on the IEEE 33-bus network. It focuses in particular on the implications of different reinforcement options on the expected annual level of network losses. The study concludes that the most effective reinforcement option depends on the anticipated load profile and growth in the location under consideration. It can be seen that energy losses have a significant impact on the choice of the most effective solution. It can also be seen that, under certain circumstances, a hybrid solution performs more effectively than either traditional reinforcement or pure smart grid solutions.
\end{abstract}

\section{Introduction}

The de-carbonisation of energy to which many countries are committed will have a significant impact on their distribution networks. Loads are likely to increase substantially, due in particular to the de-carbonisation of heating resulting in increased numbers of both ground and air sourced heat pumps, and to the de-carbonisation of transport resulting in increased take-up of electrical vehicles. At the same time, the supply side is likely to become more distributed and less controllable as a result of increasing penetration of renewable generation technologies, in particular wind and photovoltaic (PV) solar, but also including hydro and biogas. As a consequence, many and possibly most networks will require reinforcement, at all voltage levels, in the period up to 2030. Traditionally, such reinforcement has involved building additional circuits or reconductoring existing circuits, and this traditional kind of reinforcement is likely to continue as the preferred solution in many locations. However, there are a number of disadvantages to the traditional approach to reinforcement, and these disadvantages are likely to become increasingly significant. In particular:

(i) The cost of new circuits is relatively high when compared with alternative reinforcement approaches using smart-grid technologies. Pressure to reduce energy costs, and the escalating number of circuits which will require reinforcement, make the universal use of traditional reinforcement unacceptable.

(ii) The disruption caused by traditional reinforcement, and the pressure it places on resources (engineering, material and capital) also encourage the use of smarter alternatives.

(iii) Variability of take up of de-carbonised loads and generation will lead to clusters on the network, which may alter with time of day, week or year. Uniform traditional reinforcement of the whole network would be inefficient, over-providing in some locations and under-providing in others. It is difficult to predict where those clusters will develop.

(iv) Not only the location but also the rate of growth of peak loads and of distributed generation (DG) is hard to forecast accurately. As traditional reinforcement has to be adequate for a 40 year horizon, it needs to be substantial. In the event of over-estimation, it may turn out to be redundant. Smart-grid technologies are more adaptable, and can often be installed for a short period and then moved elsewhere if the anticipated load growth or DG growth fails to materialise.

\section{Reinforcement options}

These considerations require a choice to be made in each location where reinforcement becomes necessary. The options are as follows:

- Traditional reinforcement by reconductoring overhead lines, substituting cables of greater cross-section or providing additional circuits to take a share of the load.

- Smart-grid technologies including one or more of the following: demand side response, real-time thermal ratings, network automation, electrical energy storage, enhanced voltage control, soft open points (SOPs).

- Hybrid solutions, which combine traditional reinforcement with smart-grid technologies in order to make best use of the advantages of each approach.

Deciding on the best reinforcement solution is a complex task. Several criteria need to be considered, reflecting the energy trilemma of security, affordability and environment, which require careful balancing. These issues are being addressed by network operators and regulators in every country, and in particular by the ongoing fundamental review of the UK network design standard P2 [1]. The methodology on which the present paper is based builds on earlier work $[2,3]$ and balances six distinct criteria in order to recommend a solution:

(i) The cost of the solution - both capital and operating over its lifetime.

(ii) The operational flexibility for the network as a whole that will be provided by the solution, particularly with reference to an uncertain future.

(iii) The level of electrical energy losses that the solution will incur annually. These have often been excluded from calculations, but are increasingly seen as an important factor.

(iv) The effects of the solution on expected asset life. If a smart-grid solution requires frequent switching, which then shortens the lifetime of the switch, this should be factored in. 
(v) The effectiveness of the solution in deferring the need for future network reinforcement, including possibly removing the need for such reinforcement altogether, for example, when expected future load growth fails to materialise.

(vi) The capacity of the solution to accommodate future load growth and, in particular, future growth of renewable generation.

The intention is to develop models based on this methodology which will enable all six criteria to be considered together, and balanced in order to produce and recommend the most effective solutions. At the present stage of development, a model has been developed which takes into account just two of the criteria - the overall cost and the level of energy losses. This will be illustrated by a case study, following a brief literature survey of recent relevant work on network energy losses.

\section{Energy losses}

Concerns regarding energy losses in networks, both technical and non-technical, appear to have gained prominence in recent years. Sometimes this has been triggered by changes of emphasis in national regulatory frameworks. In the UK, for example, loss-inclusive network designs have been triggered to some extent by the regulator OFGEM making losses into an annual reporting requirement, with associated discretionary rewards [4]. A study from Iran considers the value of customers swapping between phases as a means of reducing technical losses [5].

Engineers from Dutch DSO Alliander considered losses from their medium-voltage (MV) grid and concluded that smart re-configuration of normally open points could achieve loss reduction worth $€ 15 \mathrm{M}$ [6]. A multi-module system developed by ABB also listed reduced losses as a benefit of their improved control system [7]. Similarly, a Portuguese network operator, in a study on load flexibility, included reduced losses in their analysis [8]

Of particular relevance to the present study, studies of a centralised voltage controller (power hardware in the loop) demonstrated reductions in losses up to $22.5 \%$ [9].

\section{Case study}

The model that has been developed to evaluate energy losses and associated costs is illustrated in the following section with reference to the case study illustrated in Fig. 1. This network is based on the standard IEEE 33-bus MV feeder, with default values for all input parameters except where stated. In order to investigate the effects of opening and closing interconnections between feeders, four distinct (but initially identical) 33-bus feeders are modelled. Feeders $\mathrm{A}$ and $\mathrm{C}$ are fed from a common busbar at primary substation $\mathrm{X}$, and have a distant point of interconnection shown as AC. Typically, there will be several other feeders, not shown, connected to this common busbar. Likewise, feeders B and $\mathrm{D}$ are fed from a common busbar at primary substation $\mathrm{Y}$, and also have a distant point of interconnection BD. Again, typically, there will be several other feeders, not shown, connected to this common busbar. There are also two other points of interconnection, between feeders $\mathrm{A}$ and $\mathrm{B}(\mathrm{AB})$ and between feeders $\mathrm{C}$ and $\mathrm{D}$ (CD). Each of these four points of interconnection can be open or closed. It is also possible to model each of them as a SOP, able to transfer a specified quantity of power in either direction.

Using default parameters, including loads and line impedances, to represent the base case in the year 2016, with all interconnectors open, the following output is obtained:

Power to each feeder: $P=3.91 \mathrm{MW}, Q=2.42 \mathrm{MVar}$

Voltages: 1.06 p.u. before transformers, 1.046 at common busbars, 0.963 at $\mathrm{AC}$ and $\mathrm{BD}, 0.960$ at $\mathrm{AB}$ and $\mathrm{CD}$.

Losses: $0.195 \mathrm{MW}$ in each feeder (5.0\%).

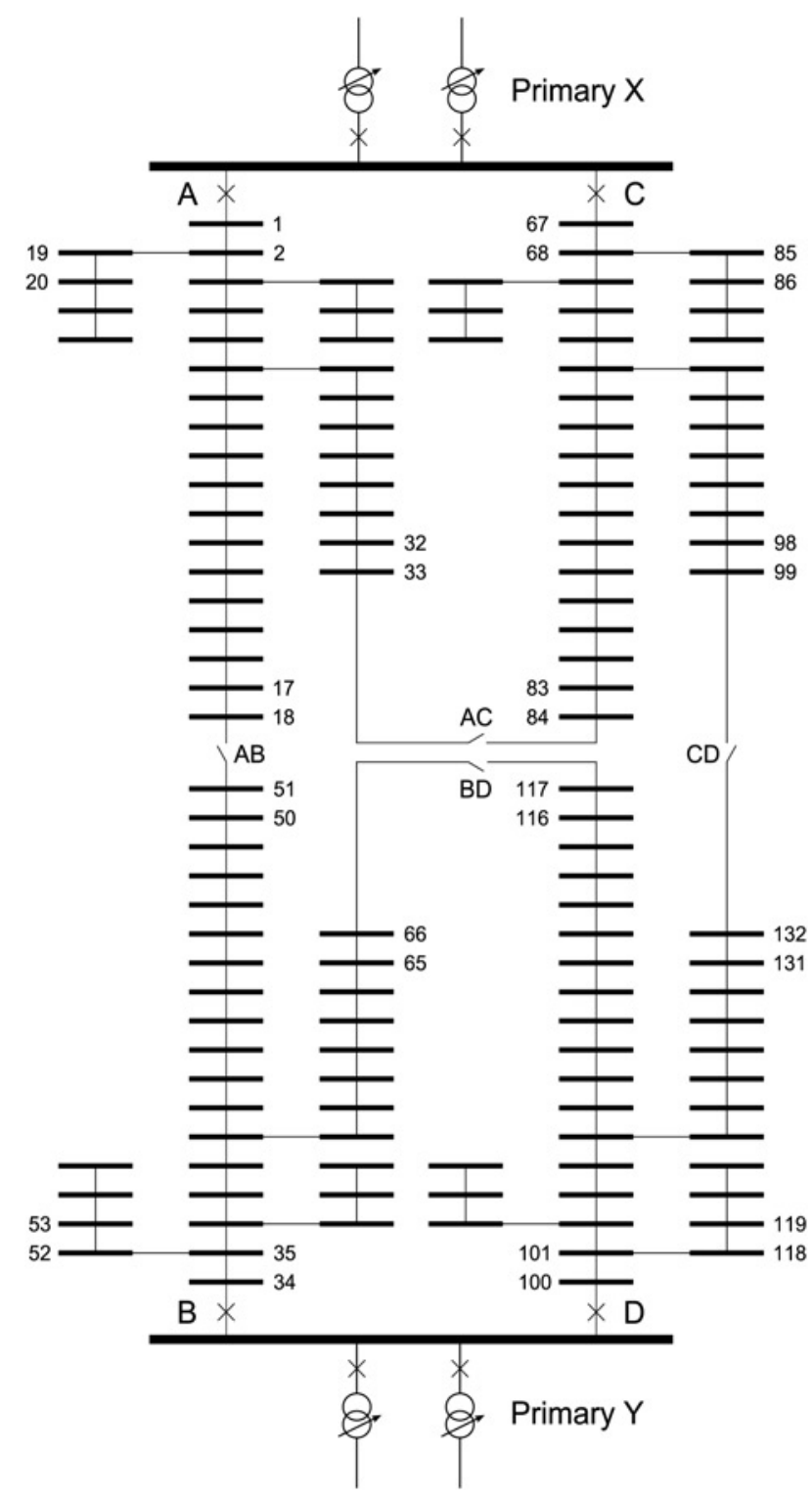

Fig. 1 Case-study network

These values are within the voltage tolerance values of $+6 \%$ to $-6 \%$ which are specified by the UK regulations (Option 1 in Table 1). Assuming that the power flows are also within line ratings, these circuits would be regarded as fit for purpose under network intact conditions. Whether they would be adequate under $(n-1)$ conditions would depend (in the UK) on the number of customers in each circuit, but this circumstance is excluded from the present study.

\subsection{Base case in 2028}

Taking a 12 year horizon, it is assumed that between 2016 and 2028 an underlying average peak load growth of $1.5 \%$ per year takes place due largely to the increased take-up of electric vehicles (EVs) and heat pumps. This on its own would lead to a $20 \%$ increase by 2028 , which could cause line ratings or voltage limits or both to be exceeded. However, it would be exacerbated by any uneven distribution of such technologies between feeders. To represent this in the case study, it is assumed that, while feeders C and D experience the average growth rate, feeder $\mathrm{A}$ has a greater number of early adopters, and its peak load grows at double the annual average, giving a $40 \%$ increase by 2028 . By contrast, it is assumed that feeder $\mathrm{B}$ is dominated by above average new renewable generation, both dispersed and concentrated. The 
Table 1 Voltages (p.u.) for options in text

\begin{tabular}{lcccc}
\hline Voltage at: option & $\begin{array}{c}\text { Feeder A } \\
\text { end at AB }\end{array}$ & $\begin{array}{c}\text { Feeder B } \\
\text { bus 50 }\end{array}$ & $\begin{array}{c}\text { Feeder B } \\
\text { bus 65 }\end{array}$ & $\begin{array}{c}\text { Feeder C/ } \\
\text { D at CD }\end{array}$ \\
\hline $\begin{array}{l}\text { present loads in 2016 } \\
\text { (Option 1) }\end{array}$ & 0.960 & 0.960 & 0.963 & 0.960 \\
$\begin{array}{l}\text { base case in 2028 } \\
\text { (Option 2) }\end{array}$ & $0.917^{\mathrm{a}}$ & $1.164^{\mathrm{a}}$ & $1.108^{\mathrm{a}}$ & $0.936^{\mathrm{a}}$ \\
$\begin{array}{l}\text { reconductor all 4 } \\
\text { feeders (Option 3) }\end{array}$ & 0.946 & $1.106^{\mathrm{a}}$ & $1.070^{\mathrm{a}}$ & 0.961 \\
$\begin{array}{l}\text { reconductor plus 2nd } \\
\text { circuit for A and B } \\
\text { (Option 4) traditional }\end{array}$ & 0.975 & 1.057 & 1.039 & 0.961 \\
$\begin{array}{l}\text { automate and close AB } \\
\text { (Option 5) }\end{array}$ & 1.044 & $1.062^{\mathrm{a}}$ & $1.088^{\mathrm{a}}$ & $0.936^{\mathrm{a}}$ \\
$\begin{array}{l}\text { automate and close all 4 } \\
\text { (Option 6) smart-grid }\end{array}$ & 1.043 & 1.053 & 1.057 & 0.962 \\
$\begin{array}{l}\text { reconductor, automate } \\
\text { and close AB (Option 7) }\end{array}$ & 1.034 & 1.040 & 1.057 & 0.962 \\
\begin{tabular}{l} 
hybrid \\
\hline
\end{tabular} & & & & \\
\hline
\end{tabular}

${ }^{a}$ Voltage infringements.

dispersed generation (typically PV) is assumed to balance out the anticipated load growth, giving a net load growth of zero between 2016 and 2018. The concentrated generation (typically neighbourhood combined heat and power (CHP) plants) is modelled by two $3 \mathrm{MW}$ generators, one at busbar 50 and one at busbar 65 in Fig. 1.

In this scenario, the real power into each feeder increases to 4.75 MW for $\mathrm{C}$ and $\mathrm{D}$, and to $5.61 \mathrm{MW}$ for feeder $\mathrm{A}$. In feeder $\mathrm{B}$, generation exceeds load, and the feeder exports $1.72 \mathrm{MW}$ through the common busbar at $\mathrm{X}$ to other feeders (including A). These power values may exceed line ratings, in particular for feeder A. What is clear is that they fall outside the permitted voltage limits, as shown in Table 1 (Option 2). In the case of $\mathrm{C}$ and $\mathrm{D}$, this is a small infringement of 0.936 at $\mathrm{CD}$. In the case of feeder $\mathrm{A}$, it is a more substantial infringement of 0.917 at the open point $\mathrm{AB}$. Also in the case of feeder $\mathrm{B}$, there will be a significant voltage rise, to 1.108 at the busbar 65 generator and to 1.164 at the busbar 50 generator.

The impact on losses is also considerable. They increase to $1.557 \mathrm{MW}$ across the four feeders, which equates to $11.6 \%$ of the net input to these feeders.

Clearly, there would need to have been some form of network reinforcement well before 2028 in order to address these voltage infringements. As stated earlier, such reinforcement could be traditional, or smart-grid technology, or a hybrid of the two. How this might apply in the case study is discussed in the following section.

\subsection{Case-study reinforcement options}

Before considering and comparing reinforcement options, it would be sensible to explore possible solutions short of reinforcement. One of these might be to make more use of tap changers in the primary substation transformers. The present study assumes an input voltage of 1.06 (output around 1.04). Can it help to make that value change with the state of the network? The problem with this approach is that we are trying to solve problems on one or two MV feeders. However there could be eight or more feeders from the primary busbar, and a tap change that would solve a problem in one of them could create a problem in another (not modelled in the present study).

A second solution could be to run the feeders with interconnection permanently closed. The issue here is that the state of the network changes, for example, whenever renewable generation starts or stops (e.g. when the sun comes out or goes in). It could be useful to close a point of interconnection for a period, and then later open it again when circumstances change. For this, at the very least a measure of automation will be required, together with control algorithms to precisely determine when an open point should be closed, or a closed point open. For greater control, an SOP might be preferred, at which the transfer of a calculated quantity of power in either direction could be assured. The combination of automation, control algorithms and possibly additional power electronics (to create an SOP) constitute a smart-grid solution, and will be discussed below.

Therefore, a reinforcement solution of some kind is required. Traditional reinforcement would typically involve installing a second circuit to share the load. A less-expensive alternative might be reconductoring the existing circuit. Both these options are modelled in the present study. Reconductoring is represented by substituting $630 \mathrm{~mm}^{2} 11 \mathrm{kV}$ trefoil for $300 \mathrm{~mm}^{2}$. This has the effect of reducing line resistance $R$ by $36.5 \%$ while increasing line reactance $X$ by $13.7 \%$. Installing a second circuit of $630 \mathrm{~mm}^{2}$ has the effect of further halving $R$.

Smart-grid technology options are represented in the model by the automation and control of one or more points of interconnection, possibly incorporating SOP functionality. These options can be deployed either instead of, or in combination with, traditional reinforcement. For each proposed solution, its effectiveness is assessed based on three criteria:

(i) Does it solve the voltage infringement?

(ii) Is it affordable? (capital and operating costs)

(iii) What is its impact on power losses?

\subsection{Case-study results}

Traditional reinforcement by reconductoring alone lifts the voltage on feeder $\mathrm{A}$ at $\mathrm{AB}$ to a just permissible 0.946 , and lifts the voltage at the ends of feeders $\mathrm{C}$ and $\mathrm{D}$ to an acceptable 0.961. It also drops the voltage on feeder B to 1.106 at busbar 50 and 1.070 at busbar 65, which are still outside limits (Table 1, Option 3). Therefore, reconductoring alone is not a sufficient solution. However, with a second circuit for feeders A and B, these voltages all fall within limits (Table 1, Option 4). So the traditional reinforcement solution of reconductoring plus a second circuit is a viable solution. The losses under this option also reduce significantly, from 1.557 to $0.573 \mathrm{MW}(4.6 \%)$.

Smart-grid technology in the form of automated switchgear installed at $\mathrm{AB}$ adjusts the voltages as shown in Table 1, Option 5. This brings feeder A within limits, but not feeders B, C or D so is not a valid solution. However, installing such smart-grid technology at all four normally open points brings all voltages within limits (Table 1, Option 6). So the smart-grid technology reinforcement solution is viable provided that it is installed at all four normally open points, not just at the most critical one. Losses for this solution are calculated at $0.941 \mathrm{MW}(7.4 \%)$.

There remains the possibility of a hybrid solution, incorporating features of both traditional reinforcement and smart-grid technology. This is represented in the model by reconductoring (but without a second circuit), plus automation of one normally open point (but not all four). The voltages at the four critical locations are shown in Table 1, Option 7 and are all within limits, indicating that this hybrid solution is also viable. Losses in this case are $0.728 \mathrm{MW}(5.8 \%)$.

One final point in this section needs to be made concerning SOPs. These are a development of an automated point of passive interconnection, where there is a single voltage and a consequent power flow between feeders, neither of which can be specified. In a SOP, the two feeder end voltages can be controlled and made different, and a specified power flow between them can be achieved. There are circumstances where this versatility of a SOP could provide a viable option where a simple automated point of interconnection could not. In the present case study, a single SOP at $\mathrm{AB}$ could solve the voltage rise issues on feeder $\mathrm{B}$ which automating $\mathrm{AB}$ did not. However, within the case-study network as a whole, there were still voltage infringements at $\mathrm{C}$ and $\mathrm{D}$, so SOP technology in this particular case study did not provide a solution. 


\section{Analysis}

In the case study presented, it can be seen that traditional, smart-grid and hybrid reinforcement options all have the potential to reinforce a network. As regarding losses, the traditional solution provides the lowest level of loss $(4.6 \%)$, followed by hybrid $(5.8 \%)$ and then smart grid $(7.4 \%)$. These levels can be costed, assuming average losses to be $80 \%$ of peak load losses, and a cost of $£ 150$ per MWh, to give annual cost of losses to be $£ 602 \mathrm{k}$, $£ 765 \mathrm{k}$ and $£ 989$ k, respectively.

As regarding costs, however, the order is likely to be reversed. Suppose the cost of an automated open point to be $£ 0.4 \mathrm{M}$ (including installation and capitalised incremental operating costs), the cost of reconductoring a feeder to be $£ 0.6 \mathrm{M}$, and the cost of installing a new circuit alongside the old one to be $£ 1.2 \mathrm{M}$. These figures would depend critically on the location and nature of the case study, and are thus typical values for the sake of illustration. Then the capital costs of the three options would be $£ 1.6 \mathrm{M}$ for the smart-grid solution, $£ 2.8 \mathrm{M}$ for the hybrid and $£ 4.8 \mathrm{M}$ for the traditional.

Balancing capital cost against reduced losses (and leaving out in the present analysis the other four criteria listed in the 'reinforcement options' section), it is clear that the preferred option will be a function of the time horizon adopted. Comparing smart grid with hybrid, the two break-even with a horizon of 5.35 years. Below that time, the additional capital cost of hybrid outweighs the saving in losses. Above that time, the saving in losses in hybrid outweighs the extra capital cost.

In the same way, comparing hybrid with traditional, the two break-even with a time horizon of 12.26 years. Below that time, the reduced capital cost of hybrid outweighs the extra losses. Above that time, the extra losses outweigh the reduction in capital cost.

\section{Conclusions}

These comparisons show that the optimal solution depends significantly on the time horizon within which the distribution network operator (DNO) is operating. Above 15 years, the traditional solution seems the best. DNOs have typically invested with longer horizons, often 40-50 years, and have chosen traditional solutions. The present network, relatively robust in countries like the UK, justifies those choices made 40-50 years ago.

However, circumstances have changed. Not only is a wide range of smart-grid solutions now available, but uncertainty about future patterns of demand and generation make such a distant horizon inappropriate. With a 7-10 year horizon, corresponding to DNO planning periods in the UK, it appears that a hybrid solution could be the best choice, giving flexibility for the re-deployment of smart-grid assets to other locations at the end of that period. Also, in cases where 3-4 years might be a more realistic horizon, then the smart-grid solution on its own could be the most appropriate. These solutions, both smart grid and hybrid, make use of a wide and ever-growing range of technologies, including one or more of demand side response, real-time thermal ratings, network automation (as adopted in the case study), electrical energy storage, enhanced voltage control, and SOPs.

This paper has shown that the most effective reinforcement option depends on the anticipated load profile and growth in the location under consideration. It can be seen that energy losses have a significant impact on the choice of the most effective solution. It can also be seen that, under certain circumstances, a hybrid solution performs more effectively than either traditional reinforcement or pure smart-grid solutions.

\section{References}

1 Energy Networks Association, Engineering Recommendation P2 Review (Phase 1): 'Consultation on future development of distribution planning network security standard', issued 29 April 2016

2 Blake, S., Taylor, P., Creighton, A.: 'The value of distributed generation for mitigating network risk'. Proc., CIRED 21st Int. Conf. on Energy Distribution, Frankfurt, 2011

3 Blake, S., Davison, P., Taylor, P., et al.: 'Use of real time thermal ratings to support customers under faulted network conditions'. Proc., CIRED 22nd Int. Conf. on Energy Distribution, Stockholm, 2013

4 Vegunta, S.C., Stapleton, S., Jewell, P., et al.: 'Impact on network losses of shorter low-voltage feeders and higher transformer density'. Paper 288, Proc., CIRED Workshop, Helsinki, 2016

5 Kalesar, B.M.: 'Customers swapping between phases for loss reduction considering daily load profile model in smart grid'. Paper 321, Proc., CIRED workshop, Helsinki, 2016

6 van Westering, W., van der Meulan, M., Bosma, W.: 'Evaluating electricity distribution network reconfiguration to minimize power loss on existing networks'. Paper 88, Proc., CIRED Workshop, Helsinki, 2016

7 Jendernalik, L., Wiedemann, T., Noglik, P., et al.: 'The German demo inside Grid4EU: field experience, lessons learnt and some aspects about cost-benefit of innovative solutions'. Paper 102, Proc., CIRED Workshop, Helsinki, 2016

8 Verdelho, M., Prata, R., Koraki, D., et al.: 'Demand flexibility benefits from the DNO perspective - a sustainable case study'. Paper 104, Proc., CIRED Workshop, Helsinki, 2016

9 Sayfutdinov, T., Lyons, P., Feeney, M.: 'Laboratory evaluation of a deterministic optimal power flow algorithm using power hardware in the loop'. Paper 117 Proc., CIRED Workshop, Helsinki, 2016 